\title{
The effect of polyhedral oligomeric silsesquioxanes (POSSs) incorporation in ethylene-propylene-diene-terpolymer (EPDM): a thermal study
}

\author{
Ignazio Blanco ${ }^{1}$ (1) $\cdot$ Traian Zaharescu ${ }^{2}$
}

Received: 28 May 2021 / Accepted: 7 July 2021 / Published online: 27 July 2021

(c) The Author(s) 2021

\begin{abstract}
A series of ethylene-propylene-diene-terpolymer (EPDM)/polyhedral oligomeric silsesquioxane (POSS) composites at different percentage of POSS were prepared and subjected to $\gamma$-irradiation. Both irradiated and non-irradiated EPDM and composites were investigated by the means of thermal analysis to verify if the presence of POSS molecules is able to reduce the oxidation level of free radicals generated during the degradation and to evaluate the effects of the irradiation. EPDM composites at 1, 3 and 5 mass $\%$ of POSS were thus degraded in a thermogravimetric (TG) balance in dynamic heating conditions $\left(25-700^{\circ} \mathrm{C}\right)$, in both inert and oxidative atmosphere by flowing nitrogen and air respectively. Thermal characterization was then completed by carrying out Differential Scanning Calorimetry (DSC) analysis from sub-ambient to better highlight the melting of the polymer and polymer composites occurring just above the room temperature. FTIR spectroscopy was also performed for the prepared samples to check the presence of the molecular filler in the composites and for the TG's residue at $700{ }^{\circ} \mathrm{C}$, in order to evaluate its nature. DSC and TGA parameters were detected and discussed to have information about the effect of the degradation's environment, the effect of irradiation on polymer stabilization and the effect of POSS content in the polymer matrix.
\end{abstract}

Keywords POSS $\cdot$ EPDM $\cdot$ Thermal stability $\cdot$ Oxidation $\cdot$ FTIR $\cdot$ Thermogravimetric analysis

\section{Introduction}

With the acronym EPDM it indicates a family of synthetic rubbers, namely terpolymers obtained from the copolymerization of ethylene (E), propylene (P) and a diene (D). The $\mathrm{M}$ is for elastomers having a saturated chain of the polyethylene type [1]. Historically the importance of EPDM is related to their ability in crosslinking via sulfur vulcanization, thus replacing ethylene propylene rubber (EPR), that contains no diene units and can only be crosslinked using radical methods such as peroxides [2]. During the gold age of the petrochemical industry, around the ' $80 \mathrm{~s}$, EPDM reached the

Ignazio Blanco

iblanco@unict.it

1 Department of Civil Engineering and Architecture and INSTM UdR, University of Catania, V. le A. Doria 6, 95125 Catania, Italy

2 INCDIE ICPE-CA, 313 Splaiul Unirii, 03138 Bucharest, Romania production of 279,000 metric tons, that means about $6 \%$ of the total synthetic rubber production with a higher growth rate than the other ones [3]. For many years EPDM family recorded the fastest growing on the markets, as regards elastomers, due to its outstanding properties. In particular, the absence of double bonds in the polymer chain backbone makes EPDM less sensitive to oxygen, thus allowing its use in outdoor applications $[4,5]$. The key of EPDM properties is represented by the easiness of cross-linking process due to the unsaturated sites on the side chain of EPDM [6]. Infact, in this terpolymer, ethylene and propylene monomers provide a saturated backbone interrupted by the incorporation of non-conjugated diene monomers, these latter are responsible for the unsaturated groups in EPDM [7]. The other side of the coin is that polymer's crosslinking leads to different degrees of degradation, thus required further EPDM's stabilization prior to the main applications. The described characteristics allow a widely use of EPDM in automotive sector [5, 8] and as an outdoor electrical insulator [9]. EPDM can be considered the main insulation material in joints and terminals of cable accessories [10, 
11] but because of the two-phase interface or electric field concentration present in these accessories, it is exposed to easy degradation in both direct or alternating high voltage current [12]. To avoid this degradation, accounted for $21 \%$ of the cable systems [13], researchers focused their attempts in the modification of the insulation material by using nanofillers, showing good results in inhibition of the degradation phenomena [14-16]. Coupling with the mentioned properties, more recently EPDM showed also considerable physical characteristics (high elasticity, abrasion and corrosion resistance) thus allowing the extension of its applications to more industrial areas [17] and again, aiming at further expand its useful life in kinds of severe environments, their thermal properties have been widely investigated $[6,7,18-20]$.

Polyhedral oligomeric silsesquioxanes (POSSs) have been identified as the ideal class of nanometric reinforcements to restrain electrical degradation, thus improving the lifetime of insulation materials [21] and enhance the resistance to the thermal degradation [22,23]. In a context of an increasingly frequent use of hybrid materials, POSSs have been covered in the last twenty years a dominant position with respect to the reinforcement of polymeric materials [24]. The incorporation (chemical or physical) of these three-dimensional nanometer size cage structures having $\mathrm{Si}$ vertices interconnected by $-\mathrm{O}-$ linkages, and substituents organic groups attached to silicon atoms gives rise to polymer nanostructured materials (PNMs) with interesting mechanical and physical properties, thus representing a radical alternative to the traditional filled polymers or polymer compositions [25].

The combination of their rigid inorganic skeleton with the organic periphery constituted by functionalized or not vertex groups, makes POSS a perfect hybrid building blocks that, as a function of the number and kind of organic groups, can be chemically built into a polymer structure as a side group of the main chain or terminating end-group [26].

The research focused on POSS-containing polymer has been growing in the recent years achieving important goals in term of thermal and mechanical stability, maintaining non-toxicity and biocompatibility [27-33]. In particular thermal methods are recognized as a very important tool in the characterization of nanoparticles for reinforcement of polymeric matrices [34-37].

Thus, with the aim to protect EPDM against accelerated degradation, we evaluated the thermal behaviour of EPDM and EPDM/POSS composites at different mass percentage (mass\%) of octa-vinyl POSS and at different level of irradiation (Fig. 1). First, the prepared composites were investigated by Fourier transform IR (FTIR) in order to verify that they corresponded to what was designed to achieve with the design and preparation. Since the melting behaviour of EPDM occurs just above room temperature, the calorimetric investigation was carried out starting from sub-ambient

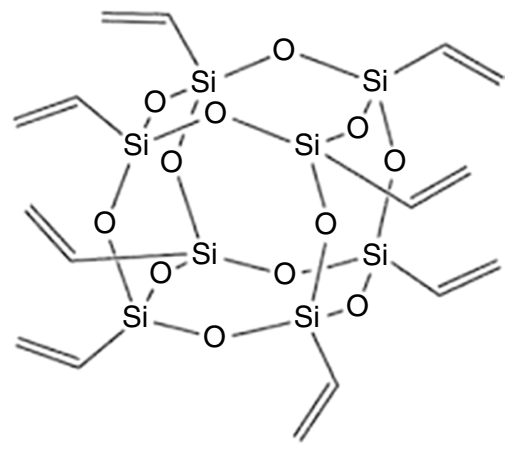

Fig. 1 Molecular structure of the octa vinyl polyhedral oligomeric silsesquioxane (POSS)

$\left(40{ }^{\circ} \mathrm{C}\right)$, whilst the resistance to the thermal degradation was evaluated by thermogravimetric analysis (TGA), extrapolating from TG measurements the initial decomposition temperature $\left(T_{\mathrm{i}}\right)$ and the amount of the solid residue at $700{ }^{\circ} \mathrm{C}$. The prepared composites and the control EPDM were also subjected to $\gamma$-irradiation to verify the effect of the irradiation process on the polymer and polymer composites degradation.

\section{Experimental}

\section{Materials}

Ethylene-propylene-diene monomer (EPDM) was purchased by DSM Elastomers (The Netherlands) as KELTAN 8550 (average molecular mass $217 \mathrm{~kg} \mathrm{~mol}^{-1}$ ). The molecular chains consist of two thirds of ethylene and one third of propylene, with a concentration of 5.5 mass\% of diene (5-ethylidene-2-norborene). Octavinyl—polyhedral oligomeric sisesquioxane (molecular mass $633.04 \mathrm{~g} \mathrm{~mol}^{-1}$ ) was purchased by Sigma Aldrich (USA). EPDM were first treated with chloroform to remove possible insoluble fraction. The defined POSS content (1, 3 and 5 mass\%) were added to the clear polymer solution, preparing separately each composite formulation. Thus, the specimens were obtained, as $1 \mathrm{~mm}$ thick foils, eliminating chloroform by volatilization at room temperature. The accelerated degradation of samples was achieved by the $\gamma$-exposure in an irradiation room provided with a ${ }^{60} \mathrm{Co}$ source, whose specific dose rate was $0.6 \mathrm{kGy} \mathrm{h}^{-1}$.

\section{FTIR analysis}

Fourier Transform Infrared (FTIR) spectroscopy was carried out in a Spectrum 100 equipment (Perkin Elmer, Waltham, MA, US). FTIR analysis was performed, aiming at verifying the presence of POSSs in the prepared samples, at r.t. 
from 4000 to $650 \mathrm{~cm}^{-1}$ with a resolution of $4.0 \mathrm{~cm}^{-1}$. An universal ATR sampling accessory was used for measurements, which were made directly on the samples without further treatment.

\section{DSC analysis}

A Mettler DSC 1 Star System (Mettler Instrument, Greifensee, Swizterland) was used to evaluate the melting behaviour of EPDM and related composites. The equipment was calibrated, in enthalpy and temperature, following the manufacturer's suggestions reported in the user manual and applied in a previous study [38]. The onset temperature $\left(T_{\text {onset }}\right)$ and enthalpy $(\Delta H)$ of melting were determined performing three scanning for each sample and reporting the averaged value, the deviation remain within $\pm 0.5 \%$. Samples of about 6.0 $10^{-3} \mathrm{~g}$, held in sealed aluminium crucibles, were heated, with a scanning rate of $10^{\circ} \mathrm{C} \mathrm{min}^{-1}$, in the rage $-40-125^{\circ} \mathrm{C}$.

\section{Thermogravimetric analysis}

EPDM and EPDM/POSS composites were thermally characterised in a Mettler Thermogravimetric Analyzer TGA 1 Star System. Following the procedure reported in the User's manual the TG equipment was calibrated by using the change of magnetic properties of three metal samples (Isatherm, Nickel-alloy and Trafoperm 86) at their Curie points $\left(148,355\right.$ and $750{ }^{\circ} \mathrm{C}$, respectively). The degradations were performed in the range $25-700{ }^{\circ} \mathrm{C}$ in dynamic mode $\left(10{ }^{\circ} \mathrm{C} \mathrm{min}-1\right)$, in inert (nitrogen flow at $0.06 \mathrm{~L} \mathrm{~min}^{-1}$ ) and oxidative (air flow at $0.06 \mathrm{~L} \mathrm{~min}^{-1}$ ) environments respectively. Before performing TG measurements, a blank run with an empty pan was carried out, in the same experimental conditions used for the samples, to correct the error in the mass determination due to the reduction of the buoyancy force on increasing temperature [39]. The blank curve obtained with the empty pan was subtracted from those containing, from time to time, about $5 \times 10^{-3} \mathrm{~g}$ of samples.

\section{Results and discussion}

FTIR spectroscopy of the control EPDM and the prepared composites were performed to check the presence of POSS in the composites. As expected, in Figs. 2 and 3, the band at about $1100 \mathrm{~cm}^{-1}$ related to the asymmetric Si-O-Si stretching and associated to the POSS cage [40], is clearly visible for the composites and not for neat EPDM, thus confirming, at least qualitatively, the presence of POSS molecules in the EPDM composites. It is worth to note that the band associated with the presence of POSS molecules is clearer for the composites irradiated at $50 \mathrm{kGy}$ (Fig. 3), whilst for the non-irradiated composites the greater or lesser presence of POSS molecules seems to influence the intensity of the band (Fig. 2).

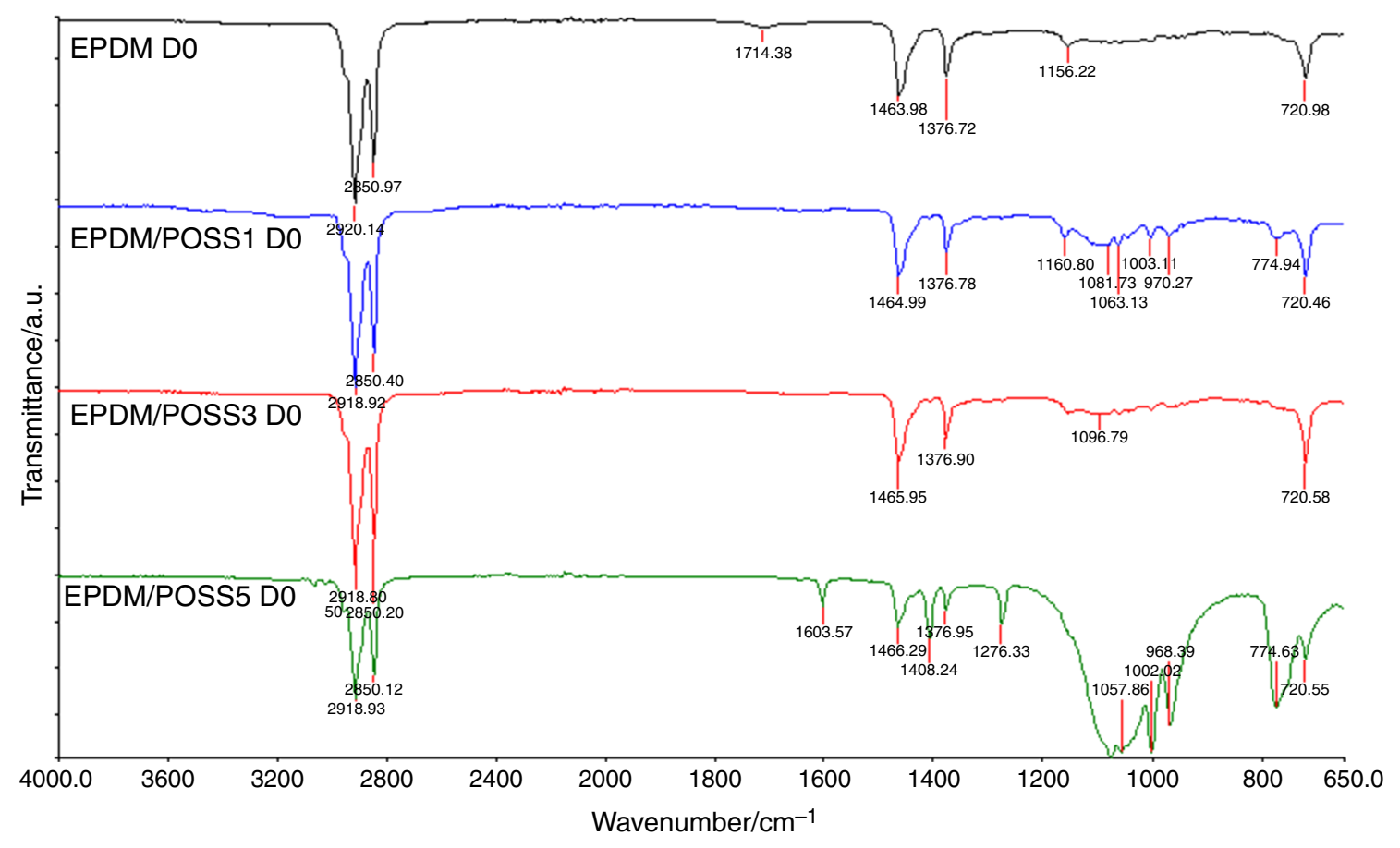

Fig. 2 FTIR spectra of pristine EPDM and EPDM/POSS 1\%; EPDM/POSS 3\%; EPDM/POSS 5\% at irradiation dose of 0 kGy 


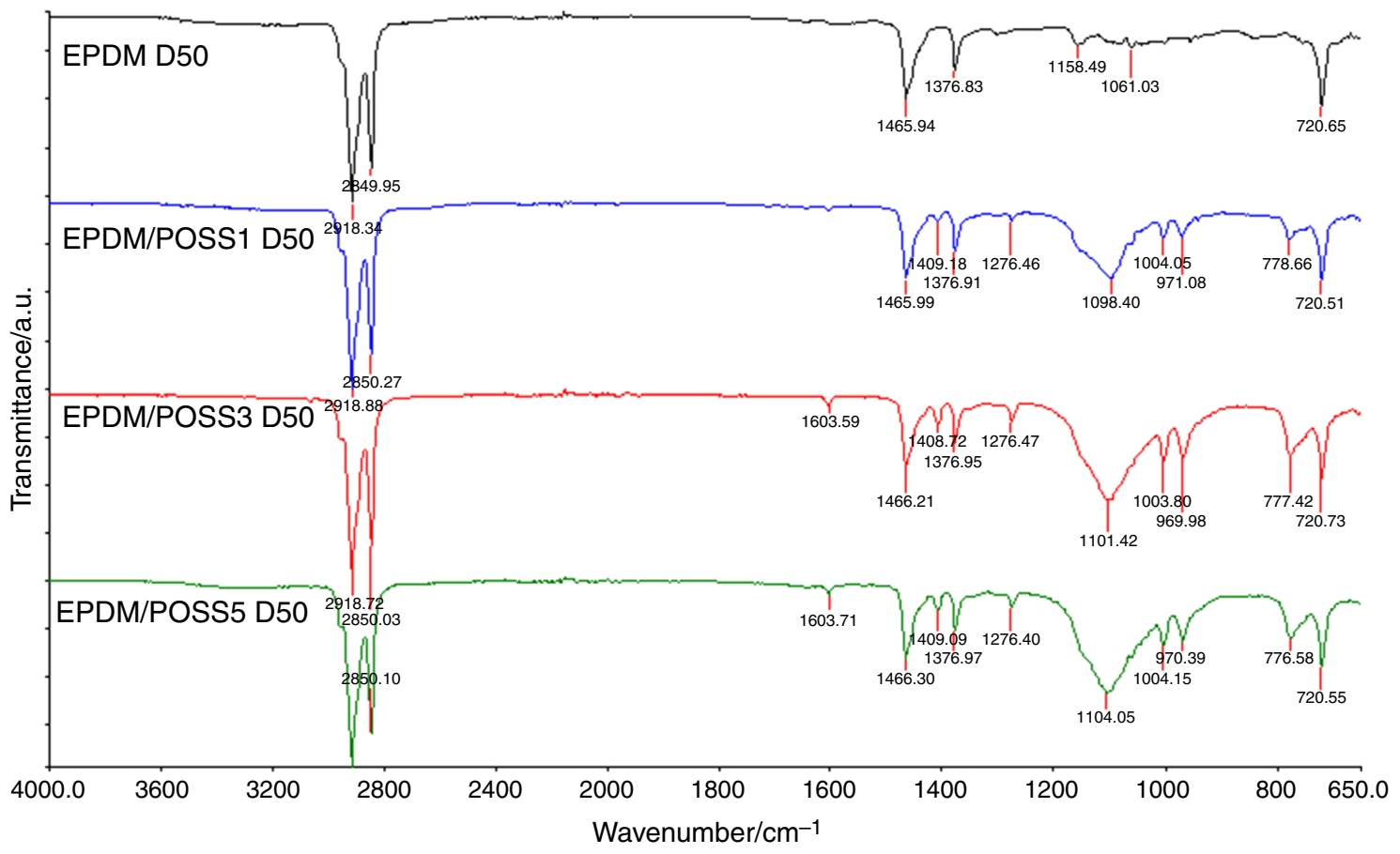

Fig. 3 FTIR spectra of pristine EPDM and EPDM/POSS 1\%; EPDM/POSS 3\%; EPDM/POSS 5\% at irradiation dose of $50 \mathrm{kGy}$

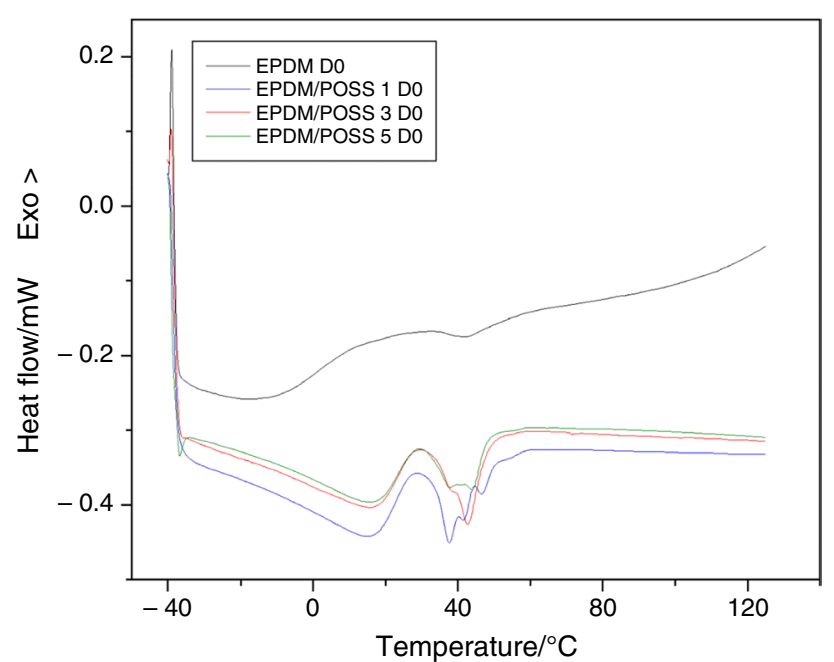

Fig. 4 DSC curves, at $10{ }^{\circ} \mathrm{C} \min ^{-1}$, under nitrogen flow for EPDM and EPDM/POSS 1\%; EPDM/POSS 3\%; EPDM/POSS 5\% at irradiation dose of $0 \mathrm{kGy}$

Control EPDM and composites, irradiated and not, were calorimetric characterised by carrying out DSC scans from 40 to $125^{\circ} \mathrm{C}$ in flowing nitrogen. This range was chosen to better highlight the melting, that for EPDM occurring at a temperature just above the ambient one. DSC curves for non-irradiated and irradiated samples are shown in Figs. 4 and 5 respectively, whilst the characteristic DSC parameters, namely onset melting temperature $\left(T_{\text {onset }}\right)$, peak

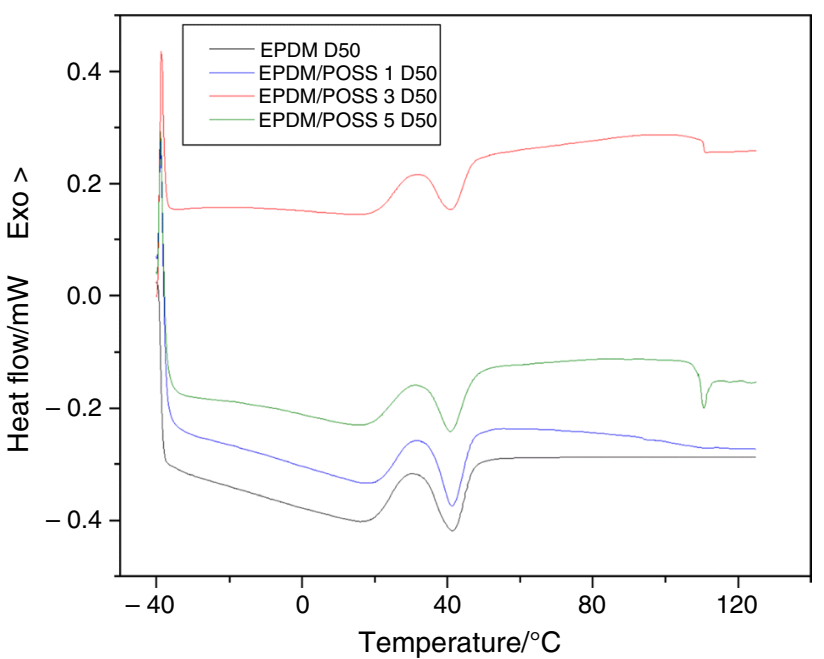

Fig. 5 DSC curves, at $10^{\circ} \mathrm{C} \mathrm{min}^{-1}$, under nitrogen flow for EPDM and EPDM/POSS 1\%; EPDM/POSS 3\%; EPDM/POSS 5\% at irradiation dose of $50 \mathrm{kGy}$

melting temperature $\left(T_{\mathrm{m}}\right)$ and enthalpy of melting $\left(\Delta H_{\mathrm{m}}\right)$, are reported in Tables 1 and 2. A thermal effect was observed for the investigated compounds before their melting, probably due to the end of the glass transition that for EPDM generally occurs at about $50{ }^{\circ} \mathrm{C}$ [41]. This effect is more pronounced for EPDM whilst it loss intensity by increasing the POSS content in the composites, probably due to the restriction of mobility for the presence of the POSS cage in the matrix 
Table 1 Onset melting Temperatures ( $\left.T_{\text {onset }}\right)$, peak melting Temperatures $\left(T_{\mathrm{m}}\right)$ and Entalphy of melting $\left(\Delta H_{\mathrm{m}}\right)$ for non irradiated EPDM and composites

\begin{tabular}{llll}
\hline Samples & $T_{\text {onset }}{ }^{\circ} \mathrm{C}$ & $T_{\mathrm{m}} /{ }^{\circ} \mathrm{C}$ & $\Delta H_{\mathrm{m}} / \mathrm{Jg}^{-1}$ \\
\hline EPDM D0 & 33.3 & 42.6 & 0.66 \\
EPDM/POSS1 D0 & 32.8 & 37.6 & 5.45 \\
EPDM/POSS3 D0 & 33.4 & 42.8 & 5.56 \\
EPDM/POSS5 D0 & 32.1 & 43.9 & 4.51 \\
\hline
\end{tabular}

Table 2 Onset melting Temperatures $\left(T_{\text {onset }}\right)$, peak melting Temperatures $\left(T_{\mathrm{m}}\right)$ and Entalphy of melting $\left(\Delta H_{\mathrm{m}}\right)$ for irradiated EPDM and composites

\begin{tabular}{llll}
\hline Samples & $T_{\text {onset }} /{ }^{\circ} \mathrm{C}$ & $T_{\mathrm{m}} /{ }^{\circ} \mathrm{C}$ & $\Delta H_{\mathrm{m}} / \mathrm{Jg}^{-1}$ \\
\hline EPDM D50 & 33.5 & 41.4 & 5.63 \\
EPDM/POSS1 D50 & 35.6 & 41.3 & 5.28 \\
EPDM/POSS3 D50 & 34.3 & 41.2 & 3.71 \\
EPDM/POSS5 D50 & 34.7 & 41.0 & 4.42 \\
\hline
\end{tabular}

[42]. As regards the data in Table 1, seem to indicate that the presence of POSS does not influence the melting behaviour of the composites with respect the control polymer. The irradiated composites seem to show a slight increase in the $T_{\text {onset }}$, which is maximum at $1 \%$ of POSS, thus indicating a minimum stabilization effect. For the irradiated composites an endothermic phenomenon was recorded just above $100{ }^{\circ} \mathrm{C}$, whose intensity increase as a function of POSS content in the polymer. Similar endothermic phenomena were observed in the past on similar symmetric POSS and were attributed to not reversible solid-solid transitions, due to the cleavage of weak secondary bonds [25]. This hypothesis seems confirmed considering that the phenomena is detected here only for the $\gamma$-irradiated samples, suggesting that the irradiation has favored this cleavage.

EPDM and EPDM/POSS composites were then degraded, in dynamic heating conditions (r.t. $-700{ }^{\circ} \mathrm{C}$ ), into the TGA equipment in both inert and oxidative environment, and their TG curves are shown in Figs. 6 and 7 for the non-irradiated samples and in Figs. 8 and 9 for the irradiated ones, reporting the percentage of un-degraded sample (1-D\%) as a function of the temperature. In Tables 3 and 4 we reported the initial decomposition temperatures $\left(T_{\mathrm{i}}\right)$, the peak temperatures $\left(T_{\mathrm{p}}\right)$ and the residue $\%$ at $700{ }^{\circ} \mathrm{C}$ for the non-irradiated EPDM and composites in inert and oxidative atmosphere respectively. Analogously, In Tables 5 and 6 we reported $T_{\mathrm{i}}$, $T_{\mathrm{p}}$ and the residue $\%$ at $700{ }^{\circ} \mathrm{C}$ for the irradiated EPDM and composites in inert and oxidative atmosphere respectively.

In the considered temperature range $\left(25-700{ }^{\circ} \mathrm{C}\right)$ it has been observed a different degradation mechanism for the control EPDM and the EPDM/POSS composites. The

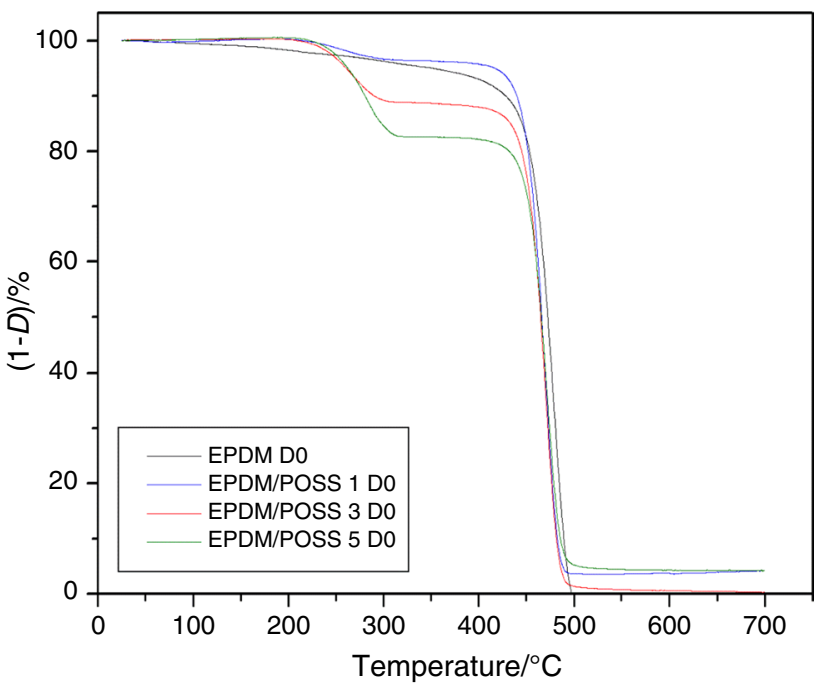

Fig. $6 \mathrm{TG}$ degradation curves, at $10{ }^{\circ} \mathrm{C} \mathrm{min}^{-1}$, under nitrogen flow for EPDM and EPDM/POSS 1\%; EPDM/POSS 3\%; EPDM/POSS 5\% at irradiation dose of $0 \mathrm{kGy} . D=(\mathrm{Wo}-\mathrm{W}) / \mathrm{Wo}$, Wo and W were the masses at the starting point and during scanning

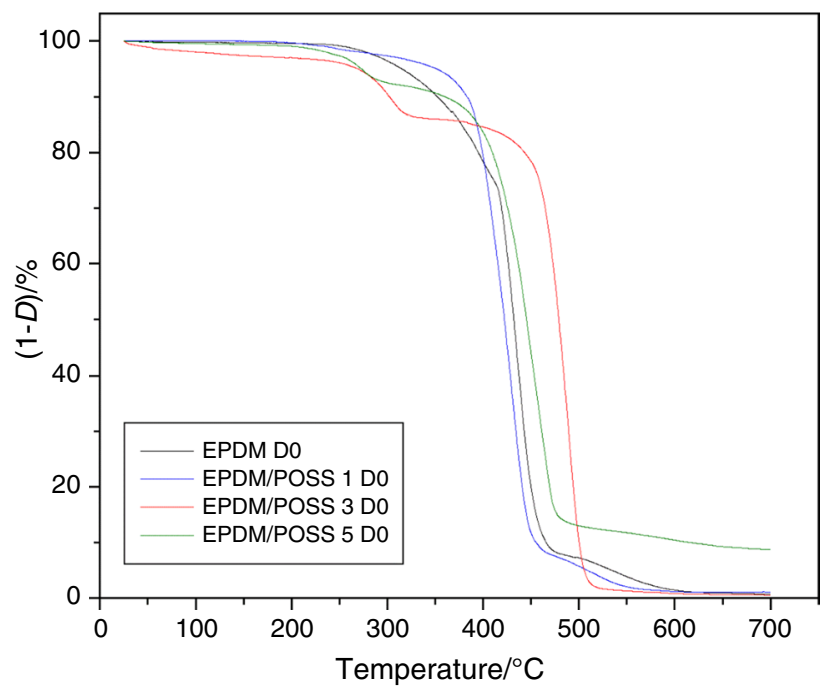

Fig. 7 TG degradation curves, at $10{ }^{\circ} \mathrm{C} \mathrm{min}^{-1}$, in static air atmosphere for EPDM and EPDM/POSS 1\%; EPDM/POSS 3\%; EPDM/ POSS $5 \%$ at irradiation dose of $0 \mathrm{kGy} . D=(\mathrm{Wo}-\mathrm{W}) / \mathrm{Wo}$, Wo and W were the masses at the starting point and during scanning

virgin polymer degraded in a single stage whilst EPDM/ POSS composites, irradiated and not, showed two different stages of degradation in both used atmospheres (Figs. 6-9). Three differences are worth to highlight: the effect of the degradation's environment, the effect of irradiation on polymer stabilization and the effect of POSS content in the polymer matrix. In inert atmosphere the first degradation stage is more evident than in oxidative environment at the same dose of irradiation, whilst the 


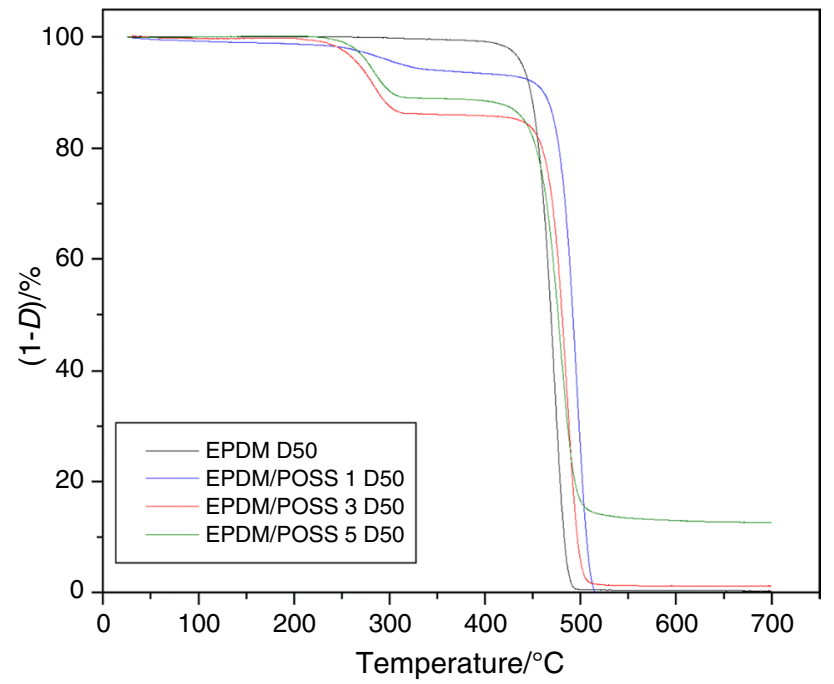

Fig. $8 \mathrm{TG}$ degradation curves, at $10{ }^{\circ} \mathrm{C} \mathrm{min}^{-1}$, under nitrogen flow for EPDM and EPDM/POSS 1\%; EPDM/POSS 3\%; EPDM/POSS 5\% at irradiation dose of $50 \mathrm{kGy} . D=(\mathrm{Wo}-\mathrm{W}) / \mathrm{Wo}$, Wo and W were the masses at the starting point and during scanning

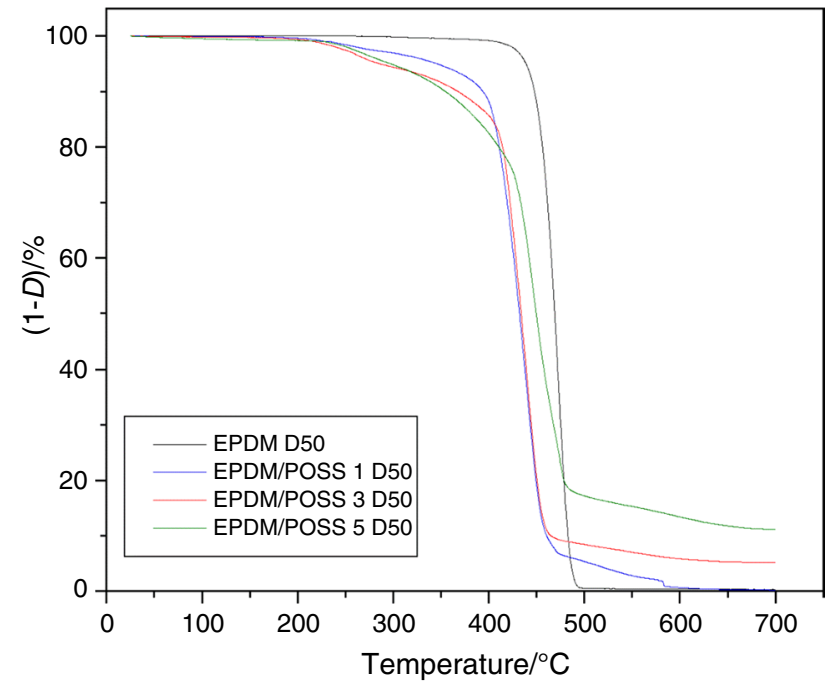

Fig. 9 TG degradation curves, at $10{ }^{\circ} \mathrm{C} \cdot \mathrm{min}^{-1}$, in static air atmosphere for EPDM and EPDM/POSS 1\%; EPDM/POSS 3\%; EPDM/ POSS $5 \%$ at irradiation dose of $50 \mathrm{kGy} . D=(\mathrm{Wo}-\mathrm{W}) / \mathrm{Wo}$, Wo and $\mathrm{W}$ were the masses at the starting point and during scanning

Table 3 Initial decomposition temperatures $\left(T_{\mathrm{i}}\right)$, peak temperatures $\left(T_{\mathrm{p}}\right)$ and residue $\%$ at $700{ }^{\circ} \mathrm{C}$ for non irradiated EPDM and composites in oxidative atmosphere

\begin{tabular}{llllll}
\hline Samples & $T_{\mathrm{i}} /{ }^{\circ} \mathrm{C}$ & $T_{\mathrm{p}} /{ }^{\circ} \mathrm{C}$ & $T_{\mathrm{i} 2} /{ }^{\circ} \mathrm{C}$ & $T_{\mathrm{p} 2} /{ }^{\circ} \mathrm{C}$ & residue/\% \\
\hline EPDM D0 & n.p.* & n.p. $*$ & 406.8 & 435.7 & 0 \\
EPDM/POSS1 D0 & 239.7 & n.d.** & 396.6 & 423.8 & 1.10 \\
EPDM/POSS3 D0 & 276.7 & 298.7 & 464.0 & 484.3 & 0.54 \\
EPDM/POSS5 D0 & 238.9 & 272.2 & 402.6 & 451.0 & 15.7 \\
\hline
\end{tabular}

*n.p. $=$ not present

**not detectable
Table 4 Initial decomposition temperatures $\left(T_{\mathrm{i}}\right)$, peak temperatures $\left(T_{\mathrm{p}}\right)$ and residue $\%$ at $700{ }^{\circ} \mathrm{C}$ for non irradiated EPDM and composites in inert atmosphere

\begin{tabular}{llllll}
\hline Samples & $T_{\mathrm{i}} /{ }^{\circ} \mathrm{C}$ & $T_{\mathrm{p}} /{ }^{\circ} \mathrm{C}$ & $T_{\mathrm{i} 2} /{ }^{\circ} \mathrm{C}$ & $T_{\mathrm{p} 2} /{ }^{\circ} \mathrm{C}$ & residue/\% \\
\hline EPDM D0 & n.p. $*$ & n.p. $*$ & 450.6 & 476.3 & 0 \\
EPDM/POSS1 D0 & 240.0 & 256.0 & 449.9 & 467.0 & 4.26 \\
EPDM/POSS3 D0 & 238.9 & 266.2 & 447.1 & 467.7 & 0.35 \\
EPDM/POSS5 D0 & 242.3 & 279.0 & 452.0 & 469.2 & 8.69 \\
\hline
\end{tabular}

*n.p. $=$ not present

Table 5 Initial decomposition temperatures $\left(T_{\mathrm{i}}\right)$, peak temperatures $\left(T_{\mathrm{p}}\right)$ and residue $\%$ at $700{ }^{\circ} \mathrm{C}$ for irradiated EPDM and composites in oxidative atmosphere

\begin{tabular}{llllll}
\hline Samples & $T_{\mathrm{i}} /{ }^{\circ} \mathrm{C}$ & $T_{\mathrm{p}} /{ }^{\circ} \mathrm{C}$ & $T_{\mathrm{i} 2} /{ }^{\circ} \mathrm{C}$ & $T_{\mathrm{p} 2} /{ }^{\circ} \mathrm{C}$ & Residue/\% \\
\hline EPDM D50 & n.p.* & n.p.* & 382.4 & 423.5 & 0 \\
EPDM/POSS1 D50 & 242.2 & 252.6 & 407.6 & 433.7 & 0.17 \\
EPDM/POSS3 D50 & 223.2 & 251.0 & 413.5 & 435.3 & 5.20 \\
EPDM/POSS5 D50 & 248.2 & 255.7 & 424.4 & 452.0 & 11.11 \\
\hline
\end{tabular}

*n.p. $=$ not present

Table 6 Initial decomposition temperatures $\left(T_{\mathrm{i}}\right)$, peak temperatures $\left(T_{\mathrm{p}}\right)$ and residue $\%$ at $700{ }^{\circ} \mathrm{C}$ for irradiated EPDM and composites in inert atmosphere

\begin{tabular}{llllll}
\hline Samples & $T_{\mathrm{i}} /{ }^{\circ} \mathrm{C}$ & $T_{\mathrm{p}}{ }^{\circ} \mathrm{C}$ & $T_{\mathrm{i} 2} /{ }^{\circ} \mathrm{C}$ & $T_{\mathrm{p} 2} /{ }^{\circ} \mathrm{C}$ & residue $\%$ \\
\hline EPDM D50 & n.p. $*$ & n.p. $*$ & 453.7 & 469.3 & 0 \\
EPDM/POSS1 D50 & 244.9 & 294.0 & 473.0 & 493.7 & 0 \\
EPDM/POSS3 D50 & 253.7 & 280.3 & 465.0 & 483.3 & 1.18 \\
EPDM/POSS5 D50 & 257.6 & 282.3 & 451.2 & 476.7 & 12.64
\end{tabular}

*n.p. $=$ not present

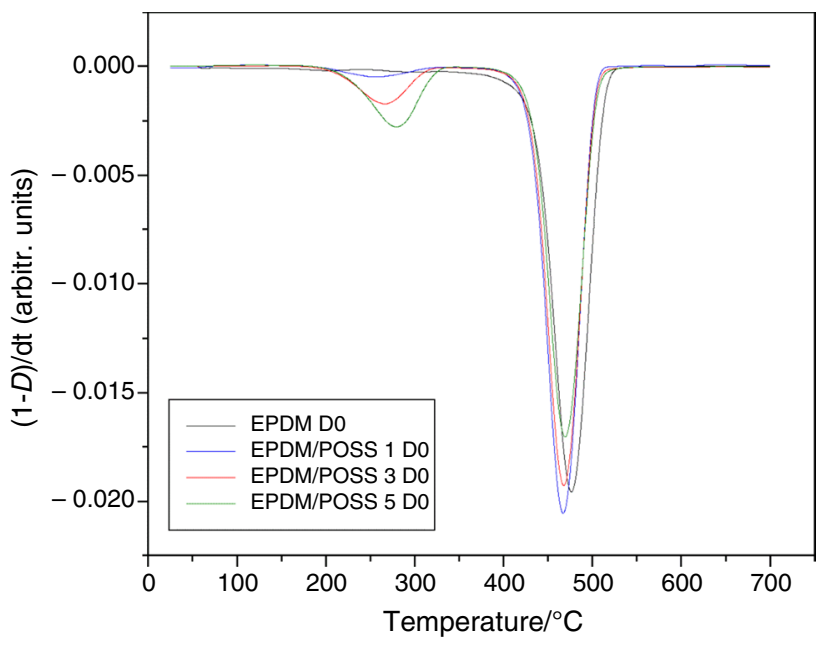

Fig. 10 DTG curves, at $10{ }^{\circ} \mathrm{C} \cdot \mathrm{min}^{-1}$, under nitrogen flow for EPDM and EPDM/POSS 1\%; EPDM/POSS 3\%; EPDM/POSS 5\% at irradiation dose of $0 \mathrm{kGy}$ 


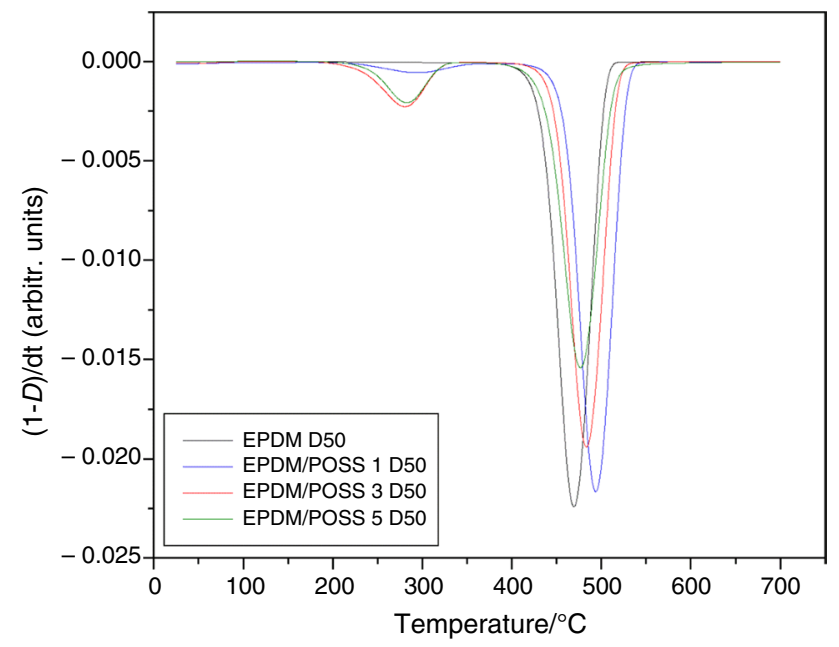

Fig. 11 DTG curves, at $10{ }^{\circ} \mathrm{C} \cdot \mathrm{min}^{-1}$, under nitrogen flow for EPDM and EPDM/POSS 1\%; EPDM/POSS 3\%; EPDM/POSS 5\% at irradiation dose of $50 \mathrm{kGy}$

samples irradiated at $50 \mathrm{kGy}$ presents a shift of this first degradation stage to higher temperature. As regards the effect of POSS content on the composites degradation, it is clearly visible a direct relationship among the intensity of the first degradation stage and the POSS content, Derivative Thermogravimetric Curves (DTG) for EPDM and composites, irradiated and not, in inert environment are shown in Figs. 10 and 11 as examples. Focusing our attention on the main degradation stage, occurring just above $400{ }^{\circ} \mathrm{C}$, if for the non-irradiated composites the presence of POSS seems to not affect particularly this degradation, from Tables 5 and 6 reporting the TG parameters for the irradiated samples, it is possible to observe a consistent increase in $T_{\mathrm{i}}$, which was higher in air than in nitrogen. By looking at the data reported in Tables 3-6 the solid residue obtained at $700{ }^{\circ} \mathrm{C}$ from the TG degradations increase as a function of POSS content in the composites, and its amount seems not influenced by the atmosphere used during the degradation. In order to confirm its siliceous nature, the residue was subjected to FTIR analysis. We reported, as an example, the FTIR plot for the residue of EPDM/POSS 3 irradiated sample (Fig. 12), from which it is possible to observe the typical band associated with the presence of silica [43].

\section{Conclusions}

EPDM- octa vinyl POSS composites at different mass percentage (mass\%) of POSS were prepared and characterised by FTIR to check the effective presence of POSS in the obtained composites. The prepared composites were thus $\gamma$-irradiated with an irradiation dose of $50 \mathrm{kGy}$ and investigated by TGA and DSC. The thermal behaviour of the irradiated samples were compared each other to verify the effect of POSS content on the thermal properties and with respect the virgin EPDM and the non-irradiated composites. DSC

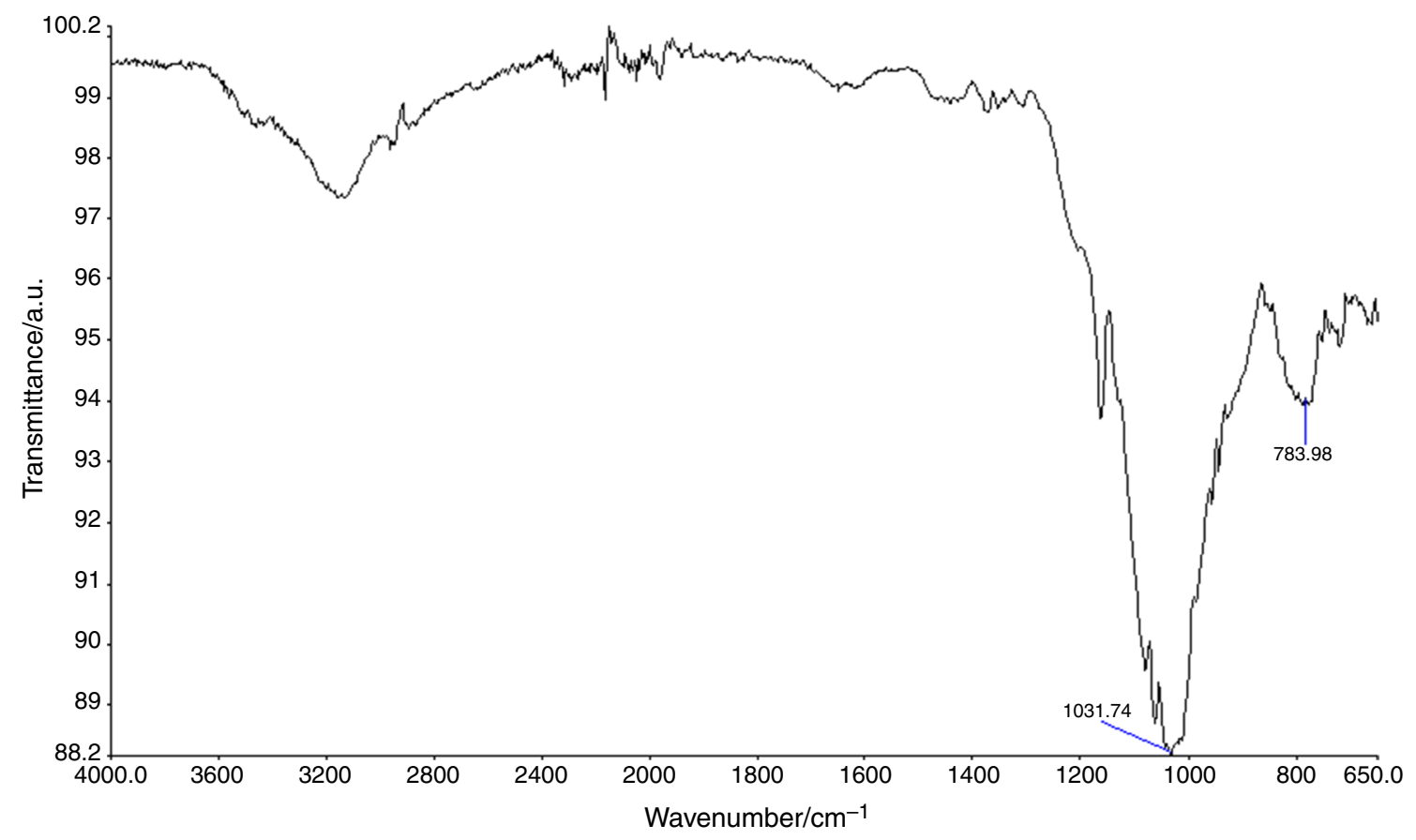

Fig. 12 FTIR spectra of the residues at $700{ }^{\circ} \mathrm{C}$, under nitrogen flow, of EPDM/POSS 5\% at irradiation dose of $50 \mathrm{kGy}$ 
analysis showed that the queue of the glass transition is more pronounced for EPDM whilst it loss intensity by increasing the content of POSS in the composites, probably due to the restriction of mobility for the presence of the POSS cage in the matrix. As regards the melting, it seems that the presence of POSS does not influence those of the composites with respect that of control polymer, but for the irradiated composites a slight increase in the $T_{\text {onset }}$ was recorded, thus indicating a minimum stabilization effect. For the irradiated composites an endothermic phenomenon was recorded above the melting and it was attributed to not reversible solid-solid transitions, due to the cleavage of weak secondary bonds. A different degradation mechanism was observed for EPDM and the composites, which degraded in two stages whilst the control polymer showed a single stage of degradation. The environmental condition of degradations seem to affect the first degradation stage, that is more evident in inert atmosphere than in oxidative one at the same dose of irradiation. A direct relationship among the intensity of the first degradation stage and the POSS content was recorded, showing an increase of this stage on increase the content of molecular filler. Finally, the main degradation stage, occurring just above $400{ }^{\circ} \mathrm{C}$, for the irradiated samples, showed an increase in the initial decomposition temperature, which was higher in air than in nitrogen.

Acknowledgements Ignazio Blanco is grateful to the University of Catania for supporting this research within the "Bando-CHANCE" and to the Department of Civil Engineering and Architecture within "Piano per la Ricerca 2016-2018-Linea Intervento 1 and 2".

Authors Contribution All authors participated to the experimental work and discussed the results and contributed to the final manuscript.

Funding Open access funding provided by Università degli Studi di Catania within the CRUI-CARE Agreement.

Open Access This article is licensed under a Creative Commons Attribution 4.0 International License, which permits use, sharing, adaptation, distribution and reproduction in any medium or format, as long as you give appropriate credit to the original author(s) and the source, provide a link to the Creative Commons licence, and indicate if changes were made. The images or other third party material in this article are included in the article's Creative Commons licence, unless indicated otherwise in a credit line to the material. If material is not included in the article's Creative Commons licence and your intended use is not permitted by statutory regulation or exceeds the permitted use, you will need to obtain permission directly from the copyright holder. To view a copy of this licence, visit http://creativecommons.org/licenses/by/4.0/.

\section{References}

1. Green MM, Wittcoff HA. Organic Chemistry Principles and Industrial Practice, Weinheim (Germania), Wiley, 2003; p. 170, ISBN978-3-527-30289-5.
2. Ouhadi T, Sabet SA, Wussow H-G, Ryan LM, Plummer L, Baumann FE, Lohmar J, Vermeire HF, Malet FLG (2014). "Thermoplastic Elastomers". Ullmann's Encyclopedia of Industrial Chemistry. Weinheim: Wiley-VCH. pp. 1-41. Doi:https://doi. org/10.1002/14356007.a26_633.pub4

3. Kaminsky W, Miri M. Ethylene propylene diene terpolymers produced with a homogeneous and highly active zirconium catalyst. J Polym Sci Part A: Polym Chem. 1985;23(8):2151-64.

4. Jestin FD, Lacoste J, Oudin NB. Photo-, thermal and natural aging of ethylene-propylene-diene monomer (EPDM) rubber used in automotive applications. Influence of carbon black, crosslinking and stabilizing agents. Polym Degrad Stab. 2000;67:469-77.

5. Ginic-Markovic M, Choudhury NR, Dimopoulos M, Matisons JG. Weatherability of coated EPDM rubber compound by controlled UV irradiation. Polym Degrad Stab. 2000;69(2):157-68.

6. Wang W, Qu B. Photo- and thermo-oxidative degradation of photocrosslinked ethylene-propylene-diene terpolymer. Polym Degrad Stab. 2003;81:531-7.

7. Gamlin C, Markovic MG, Dutta NK, Choudhury NR, Matisons JG. Structural effects on the decomposition kinetics of EPDM elastomers by high-resolution TGA and modulated TGA. J Therm Anal Calorim. 2000;59:319-36.

8. Sugiura M, Horii M, Hayashi H, Sasayama M. Application of sepiolite to prevent bleeding and blooming for EPDM rubber composition. Appl Clay Sci. 1996;11:89-97.

9. Moreno VM, Gorur RS. Effect of long-term corona on nonceramic outdoor insulator housing materials. IEEE Trans Dielectr Electr Insul. 2001;8:117-28.

10. Bouguedad D, Mekhaldi A, Jbara O, Rondot S, Hadjadj A, Douglade J, Dony Ph. Physico-chemical study of thermally aged EPDM used in power cables insulation. IEEE Trans Dielectr Electr Insul. 2016;22:3207-15.

11. Christen T, Donzel L, Greuter F. Nonlinear resistive electric field grading part 2: materials and applications. IEEE Electr Insul Mag. 2011;27(2):18-29.

12. Wang X, Wang CC, Wu K, Tu DM. An improved optimal design scheme for high voltage cable accessories. IEEE Trans Dielectr Electr Insul. 2014;21:5-15.

13. Zhang X, Gockenbach E. Component reliability modeling of distribution systems based on the evaluation of failure statistics. IEEE Trans Dielectr Electr Insul. 2007;14:1183-91.

14. Lewis TJ. Interfaces nanometric dielectrics. J Phys D: Appl Phys. 2005;38:202-12.

15. Wang YN, Wu JD, Yi Y. Nanostructures and space charge characteristics of $\mathrm{MgO} / \mathrm{LDPE}$ nanocomposites. IEEE Trans Dielectr Electr Insul. 2017;24:2390-9.

16. Nelson JK, Hu Y. Nanocomposite dielectrics-properties and implications. J Phys D: Appl Phys. 2005;38:213-22.

17. Snijders EA, Boersma A, van Baarle B, Gijsman P. Effect of dicumyl peroxide crosslinking on the UV stability of ethylenepropylene-diene (EPDM) elastomers containing 5-ethylene2-norbornene (ENB). Polym Degrad Stab. 2005;89(3):484-91.

18. Zaharescu T, Meltzer V, Vilcu R, Oprea D. Evaluation of the compatibility of EPDM and IIR I specific heat capacity. J Therm Anal Calorim. 1998;53:255-62.

19. Acharya H, Pramanik M, Srivastava SK, Bhowmick AK. Synthesis and evaluation of high-performance Ethylene-PropyleneDiene Terpolymer/Organoclay Nanoscale Composites. J Appl Polym Sci. 2004;93:2429-36.

20. Abadir EF. Mechanism and kinetics of the non-isothermal degradation of ethylenepropylene diene monomer (EPDM). J Therm Anal Calorim. 2013;114:1409-13.

21. Du B, Su J, Tian M, Han T, Li J. Understanding trap effects on electrical treeing phenomena in EPDM/POSS composites. Sci Rep. 2018;8:8481. 
22. Zaharescu T. Radiation processing analysis of aged EPDM/ vinyl-POSS hybrid systems. J Therm Anal Calorim. 2019;138:2367-74.

23. Zaharescu T, Blanco I, Bottino FA. Surface antioxidant activity of modified particles in POSS/EPDM Hybrids. Appl Surf Sci. 2020;509:144702.

24. Lichtenhan JD, Pielichowski K, Blanco I. POSS-based polymers. Polymers. 2019;11(10):1727.

25. Blanco I, Abate L, Bottino FA. Mono substituted octaphenyl POSSs: the effects of substituents on thermal properties and solubility. Thermochim Acta. 2017;655:117-23.

26. Haddad TS, Lichtenhan JD. Hybrid organic-inorganic thermoplastics: styryl-based polyhedral oligomeric silsesquioxane polymers. Macromolecules. 1996;29(22):7302-4.

27. Devaux E, Rochery M, Bourbigot S. Polyurethane/clay and polyurethane/POSS nanocomposites as flame retarded coating for polyester and cotton fabrics. Fire Mater. 2002;26:149-54.

28. García O, Sastre R, García-Moreno I, Martín V, Costela A. New laser hybrid materials based on POSS copolymers. J Phys Chem C. 2008;112:14710-3.

29. Wu J, Mather PT. POSS polymers: physical properties and biomaterials applications. Polym Rev. 2009;49:25-63.

30. Nguyen TP. Polymer-based nanocomposites for organic optoelectronic devices. Rev Surf Coat Technol. 2011;206:742-52.

31. Li L, Li X, Yang R. Mechanical, thermal properties, and flame retardancy of PC/ultrafine octaphenyl-POSS composites. J Appl Polym Sci. 2012;124:3807-14.

32. Blanco I, Bottino FA, Cicala G, Cozzo G, Latteri A, Recca A. Synthesis and thermal characterization of new dumbbell shaped POSS/PS nanocomposites: Influence of the symmetrical structure of the nanoparticles on the dispersion/aggregation in the polymer matrix. Polym Compos. 2015;36(8):1394-400.

33. Raftopoulos KN, Pielichowski K. Segmental dynamics in hybrid polymer/POSS nanomaterials. Progr Polym Sci. 2016;52:136-87.

34. Catauro M, Tranquillo E, Dal Poggetto G, Pasquali M, Dell'Era A, Vecchio CS. Influence of the heat treatment on the particles size and on the crystalline phase of $\mathrm{TiO}_{2}$ synthesized by sol-gel method. Materials. 2018;11(8):2364.
35. Catauro M, Renella RA, Papale F, Vecchio Ciprioti S. Investigation of bioactivity, biocompatibility and thermal behavior of sol-gel silica glass containing a high PEG percentage. Mater Sci Eng C. 2016;61:51-5.

36. Lazzara G, Milioto S. Dispersions of nanosilica in biocompatible copolymers. Polym Degrad Stabil. 2010;95(4):610-7.

37. Cavallaro G, Lazzara G, Milioto S, Parisi F, Sparacino V. Thermal and dynamic mechanical properties of beeswax-halloysite nanocomposites for consolidating waterlogged archaeological woods. Polym Degrad Stabil. 2015;120:220-5.

38. Abate L, Badea E, Blanco I, Della GG. Heat capacities and enthalpies of solid-solid transitions and fusion of a series of eleven primary alkylamides by differential scanning calorimetry. J Chem Eng Data. 2008;53(4):959-65.

39. Vyazovkin S, Chrissafis K, Di Lorenzo ML, Koga N, Pijolat M, Roduit B, Sbirrazzuoli N, Suñol JJ. ICTAC kinetics committee recommendations for collecting experimental thermal analysis data for kinetic computations. Thermochim Acta. 2014;590:1.

40. Park ES, Ro HW, Nguyen CV, Jaffe RL, Yoon DY. Infrared spectroscopy study of microstructures of poly(silsesquioxane)s. Chem Mater. 2008;20:1548-54.

41. Gu Z, Zhang X, Bao C, Xue M, Wang H, Tian X. Crosslinkingdependent relaxation dynamics in Ethylene-Propylene-Diene (EPDM) Terpolymer above the glass transition temperature. J Macromolecular Sci Part B. 2015;54(5):618-27.

42. Blanco I, Bottino FA. The influence of the nature of POSSs cage's periphery on the thermal stability of a series of new bridged POSS/PS nanocomposites. Polym Degrad Stabil. 2016;121:180-6.

43. Fina A, Tabuani D, Carniato F, Frache A, Boccaleri E, Camino G. Polyhedral oligomeric silsesquioxanes (POSS) thermal degradation. Thermochim Acta. 2006;440:36.

Publisher's Note Springer Nature remains neutral with regard to jurisdictional claims in published maps and institutional affiliations. 